\title{
Diagnostic performance of Des- $\gamma$-carboxy prothrombin (DCP) for Hepatocellular carcinoma: A Bivariate Meta-analysis
}

\author{
P. GAO, M. LI, Q. B. TIAN, D. W. LIU* \\ Department of Epidemiology and Biostatistics, School of Public Health, Hebei Medical University, No. 361 Zhongshan East Road, Shijiazhuang, \\ 050017, Hebei Province, China
}

${ }^{\star}$ Correspondence: dwliu1956@yahoo.com.cn

Received September 8, 2011 / Accepted September 23, 2011

\begin{abstract}
Serum markers are needed to be developed to specifically diagnose Hepatocellular carcinoma (HCC). Des- $\gamma$-carboxy prothrombin (DCP) is a promising tool with limited expense and widely accessibility, but the reported results have been controversial. In order to review the performance of DCP for the diagnosis of HCC, the meta-analysis was performed. After a systematic review of relevant studies, the sensitivity, specificity, positive and negative likelihood ratios (PLR and NLR, respectively) were pooled using a bivariate meta-analysis. Potential between-study heterogeneity was explored by meta-regression model. The post-test probability and the likelihood ratio scattergram to evaluate clinical usefulness were calculated. Based on literature review of 20 publications, the overall sensitivity, specificity, PLR and NLR of DCP for the detection of HCC were 67\% (95\%CI, 58\%-74\%), 92\% (95\%CI, 88\%-94\%), 7.9 (95\%CI, 5.6-11.2) and 0.36 (95\%CI, 0.29-0.46), respectively. The area under the bivariate summary receiving operating characteristics curve was 0.89 (95\%CI, 0.85-0.92). Significant heterogeneity was present. In conclusion, the major role of DCP is the moderate confirmation of HCC. More prospective studies of DCP are needed in future.
\end{abstract}

Key words: hepatocellular carcinoma, des- $\gamma$-carboxy prothrombin, pooled analysis, sandwich ELISA, diagnostic test

Hepatocellular carcinoma (HCC) is one of the most common cancers in the world [1], it is the fifth most prevalent cancer globally and the third leading cause of cancer related deaths [2]. Some studies reported that the median survival of HCC was only 3-6 months after the onset of symptoms [3]. However, if HCC can be detected when tumor lesions are small and patients asymptomatic, the HCC is potentially curable [4]. For example, the 5-year overall survival rates of patients have exceeded $70 \%$ after orthotopic liver transplantation [5].

Thus, regular screening among the high risk population including patients with chronic hepatitis and cirrhosis would benefit in detecting the disease in an early curable stage, yield a long-term survival and decrease mortality of $\operatorname{HCC}[6,7]$. Currently, liver biopsy is the gold standard for this purpose. Unfortunately, due to its invasiveness, not everyone can endure it. Imaging technology including ultrasonography, helical computed tomography, and magnetic resonance imaging have permitted the detection of smaller sized tumors $(1 \mathrm{~cm})$ in early carcinogenesis $[8,9]$. However, the diagnostic performance of these modalities varies widely depending on the experience of the examiner. Tumor markers for HCC thus clearly are needed. AFP is the most commonly used serum marker in diagnosing HCC. However, AFP levels may be normal in up to $40 \%$ of patients with HCC, particularly in patients with small HCC [10]. Moreover, the elevated AFP level of some patients with cirrhosis or chronic hepatitis may be observed as well [11]. There is a need to develop additional sensitive and specific serum markers used to diagnose HCC in an early stage.

In 1984, Liebman et al reported that 69 out of 76 patients (91\%) with HCC had abnormally high levels of DCP. They also described that only three out of 28 cases $(11 \%)$ with chronic active hepatitis showed an increased DCP level [12]. Since then, many studies had evaluated the usefulness of DCP in the diagnosis of patients with HCC, but results have been controversial and difficult to convince as small sample size. Therefore, the objective of this study was to systematically review the diagnostic accuracy of DCP for HCC with likelihood ratios and other performance indicators, and explore 
reasons behind the heterogeneous results using meta-regression method.

\section{Materials and methods}

Search strategy. Serum DCP levels were measured by conventional enzyme immunoassay (EIA) kit (Eitest MONO P-II, Eisai, Tokyo, Japan) before 1997. Because of its low sensitivity to detect small HCC, it was replaced by some ELISA kits which are simple and possess a much higher sensitivity. To ensure a high quality of the included studies, the literatures using the conventional kit were excluded from this study.

Literature search was carried out using PubMed, OVID, the China Biological Medicine Database (CBM) and Chinese National Knowledge Infrastructure (CNKI) (01/1997-07/2011). The search terms were used as follows: hepatocellular carcinoma, small hepatocellular carcinoma, HCC, liver cancer, des-gammacarboxy prothrombin, des- $\gamma$-carboxy prothrombin, DCP, PIVKA-II, Protein Induced by Vitamin K Absence, diagnosis, detection, early detection. Both free text and $\mathrm{MeSH}$ search for keywords were employed. No language limitations were used. Additional studies were identified via a manual review of the reference lists of identified studies and review articles.

Studies were included if they met the following inclusion criteria: [1] The studies evaluated the performance of DCP for the diagnosis of HCC with prospective or retrospective design. The performance of DCP could be assessed alone or in comparison to other tests. [2] The diagnosis of HCC was made based on histological examination or by the appropriate imaging characteristics as defined by accepted guidelines [4, 13]. [3] The studies detecting DCP concentration in serum were included, but the studies addressing detection in tissue and other body fluids were excluded.

Two reviewers (Ping Gao, Man Li) independently assessed eligible articles for inclusion. Disagreements were resolved by discussion.

Data extraction and quality assessment. Data were extracted on: [1] author, year of publication and journal; [2] study design; [3] performance of the reference standard; [4] performance of the index test; [5] data for two-by-two table; [6] characteristics of the patients.

Study quality was assessed using the QUADAS tool which is structured as a list of 14 questions. Each question should be answered "yes", "no", or "unclear" [14]. Two items were not assessed, one of which is the item of "Were the same clinical data available when test results were interpreted as would be available when the test is used in practice?", because the reference standard in our research did not rely on clinical information; the other is the item of "Were uninterpretable/intermediate test results reported?", because the DCP concentration was determined by ELISA kits, there was no uninterpretable/intermediate result. Results are presented in graphs. We did not calculate a summary score estimating the overall quality of an article since using summary scores to identify high quality studies is problematic [15].
Data analysis. Bivariate random effects approach was used to summarize the sensitivity, specificity, PLR, NLR, diagnostic odds ratio (DOR) and construct a bivariate sROC curve [16]. The bivariate model is considered as a more valid statistical model for diagnostic meta-analysis. Covariates can be added to the bivariate model and they lead to separate effects on sensitivity and specificity. This means that we can explicitly test whether there is a difference in sensitivity, specificity, or both.

As a potential cause of heterogeneity, threshold/cut off effect was tested with the Spearman correlation coefficient. Heterogeneity induced by factors other than threshold/cut-off effect was assessed by means of the Cochran Q method and by the test of inconsistency $\left(\mathrm{I}^{2}\right)$ [17]. Meta-regression model can be used to explore sources of between-study heterogeneity. The following sources of heterogeneity were addressed: ethnicity (Asian vs. Caucasian), etiology (HBV vs. HCV), control (CH/LC vs. LC), small HCC (yes vs. no), and gender (mixed vs. male) as covariates. Once reasons of heterogeneity were found, summary estimate of sensitivity, specificity, PLR, NLR, DOR were also used in the subgroup. The hierarchical summary receiver operating characteristic (HSROC) curves of the subgroups were also plotted [18].

Publication bias was examined using Deek's funnel plot of lnDOR against $1 /$ sqrt(effective sample size), and associated regression test of asymmetry [19].

Clinical Utility of the Index test. The clinical or patientrelevant utility of a diagnostic test was evaluated using the likelihood ratios to calculate post-test probability (PTP). PTP can be read either from the Probability Modifying Plot [20], or from the Fagan's nomogram [21].

The likelihood ratio scattergram was plotted to suggest whether the diagnostic test is useful for confirmation or exclusion of HCC [22]. If the summary point of likelihood ratios is in the Left Upper Quadrant, the Index test is useful for confirmation and exclusion of the disease; In the Right Upper Quadrant, it is useful for confirmation only; In the Left Lower Quadrant, it is useful for exclusion only and in the Right Lower Quadrant means no role for confirmation and exclusion.

All analyses were performed using STATA 11.0 (College Station, TX), and the methodological quality graph was plotted using the Review Manager 5.0 (The Cochrane Library).

\section{Results}

Search results and methodological quality of included studies. The 193 relevant articles were searched, of which 34 studies were eligible for inclusion, based on title and abstract. After assessment of the full text articles, 20 relevant articles (19 in English [23-41] and 1 in Chinese [42]) including 5911 patients were available. A list of all the details abstracted from included studies was provided in table 1 .

Figure 1 showed the overall methodological quality of the 20 included studies. In the 20 studies, only 3 studies evaluated 


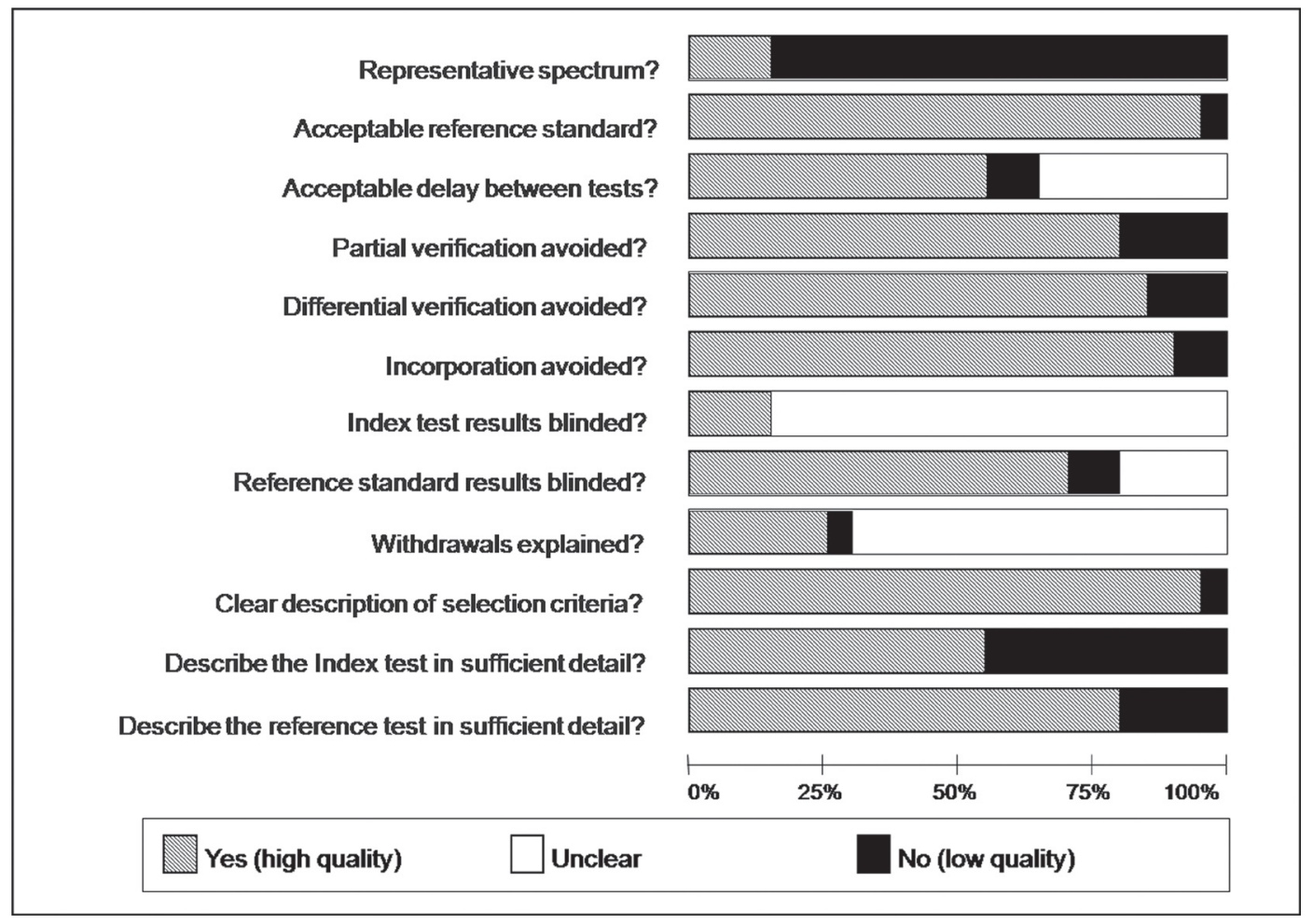

Figure 1. Methodological quality graph: Review authors' judgments about each methodological quality item presented as percentages across all 20 included studies.

Table 1 Characteristics of the Included Studies

\begin{tabular}{|c|c|c|c|c|c|c|c|c|c|c|c|}
\hline Author & $\begin{array}{c}\text { Study/Center } \\
\text { Description }\end{array}$ & $\mathrm{TP}$ & $\mathrm{FP}$ & $\mathrm{FN}$ & $\mathrm{TN}$ & $\mathrm{N}$ & Threshold & $\begin{array}{c}\text { Blind } \\
\text { Design }\end{array}$ & Ethnicity & Etiology & $\begin{array}{l}\text { Small } \\
\mathrm{HCC}^{\mathrm{c}}\end{array}$ \\
\hline Wang et al.(2005) & Retrospective, one center & 47 & 9 & 14 & 57 & 127 & $40 \mathrm{mAU} / \mathrm{ml}$ & No & Asian & $\mathrm{HBV} / \mathrm{HCV}$ & No \\
\hline Marrero et al.(2003) & Retrospective, one center & 50 & 5 & 5 & 99 & 159 & $125 \mathrm{mAU} / \mathrm{ml}$ & Yes & Caucasian & $\mathrm{HCV}$ & No \\
\hline Sharma et al.(2010) & Retrospective, one center & 57 & 3 & 13 & 65 & 138 & $6.98 \mathrm{ng} / \mathrm{ml}$ & No & Asian & $\mathrm{HBV} / \mathrm{HCV}$ & No \\
\hline Cui et al.(2003) & Retrospective, one center & 64 & 13 & 56 & 77 & 210 & $40 \mathrm{mAU} / \mathrm{ml}$ & No & Asian & HBV & No \\
\hline Okuda et al.(1999) & Retrospective, Unclear & 36 & 9 & 24 & 108 & 177 & $40 \mathrm{mAU} / \mathrm{ml}$ & No & Asian & $\mathrm{HCV}$ & No \\
\hline Mita et al.(1998) & Retrospective, Unclear & 56 & 3 & 35 & 54 & 148 & $40 \mathrm{mAU} / \mathrm{ml}$ & No & Asian & $\mathrm{HCV}$ & Yes \\
\hline Sterling et al.(2009) & Prospective, 7 centers & 29 & 31 & 45 & 267 & 372 & $7.5 \mathrm{ng} / \mathrm{ml}$ & Yes & Caucasian & $\mathrm{HCV}$ & No \\
\hline Durazo et al.(2008) & Retrospective, one center & 125 & 14 & 19 & 82 & 240 & $84 \mathrm{mAU} / \mathrm{ml}$ & Yes & Asian & $\mathrm{HBV} / \mathrm{HCV}$ & No \\
\hline Nakamura et al.(2006) & Retrospective, multicenter & 790 & 10 & 571 & 338 & 1709 & $40 \mathrm{mAU} / \mathrm{ml}$ & No & Asian & $\mathrm{HCV}$ & No \\
\hline Sassa et al.(1999) & Retrospective, one center & 27 & 2 & 34 & 132 & 195 & $40 \mathrm{mAU} / \mathrm{ml}$ & No & Asian & $\mathrm{HCV}$ & Yes \\
\hline Volk et al.(2007) & Retrospective, one center & 72 & 12 & 12 & 157 & 253 & $150 \mathrm{mAU} / \mathrm{ml}$ & Yes & Caucasian & Mixed $^{\mathrm{a}}$ & No \\
\hline Yoon et al.(2009) & Prospective, one center & 55 & 3 & 51 & 97 & 206 & $40 \mathrm{mAU} / \mathrm{ml}$ & No & Asian & $\mathrm{HBV}$ & No \\
\hline Kuromatsu et al.(1997) & Retrospective, Unclear & 58 & 6 & 71 & 77 & 212 & $40 \mathrm{mAU} / \mathrm{ml}$ & No & Asian & $\mathrm{HCV}$ & No \\
\hline Beale et al.(2008) & Retrospective, Unclear & 39 & 8 & 11 & 33 & 91 & $20.24 \mathrm{ng} / \mathrm{ml}$ & No & Caucasian & ALD and NAFLD ${ }^{b}$ & No \\
\hline Nomura et al.(1999) & Retrospective, Unclear & 10 & 2 & 26 & 47 & 85 & $40 \mathrm{mAU} / \mathrm{ml}$ & No & Asian & Mixed $^{\mathrm{a}}$ & Yes \\
\hline Baek et al.(2009) & Retrospective, one center & 189 & 32 & 38 & 68 & 327 & $40 \mathrm{mAU} / \mathrm{ml}$ & No & Asian & HBV & No \\
\hline Bachtiar et al.(2010) & Retrospective, 4 centers & 92 & 5 & 32 & 91 & 220 & $4.5 \mathrm{ng} / \mathrm{ml}$ & No & Asian & $\mathrm{HBV} / \mathrm{HCV}$ & Unclear \\
\hline Lok et al.(2010) & Prospective, multicenter & 29 & 11 & 10 & 66 & 116 & $40 \mathrm{mAU} / \mathrm{ml}$ & Yes & Caucasian & $\mathrm{HCV}$ & Yes \\
\hline Marrero et al.(2009) & Retrospective, 7 centers & 310 & 125 & 109 & 292 & 836 & $150 \mathrm{mAU} / \mathrm{ml}$ & Yes & Caucasian & Mixed $^{\mathrm{a}}$ & No \\
\hline XH et al.(2002) & Retrospective, one center & 31 & 4 & 29 & 26 & 90 & $40 \mathrm{mAU} / \mathrm{ml}$ & No & Asian & HBV & No \\
\hline
\end{tabular}

Note: TP, true positive; FP, false positive; FN, false negative; TN, true negative.

${ }^{a}$ Mixed refers to the etiology including HBV infection, HCV infection, alcohol and others.

${ }^{\mathrm{b}} \mathrm{ALD}$ and NAFLD, alcoholic and non-alcoholic fatty liver diseases.

'Small HCC, all of the tumors were $\leq 3 \mathrm{~cm}$ in diameter. 


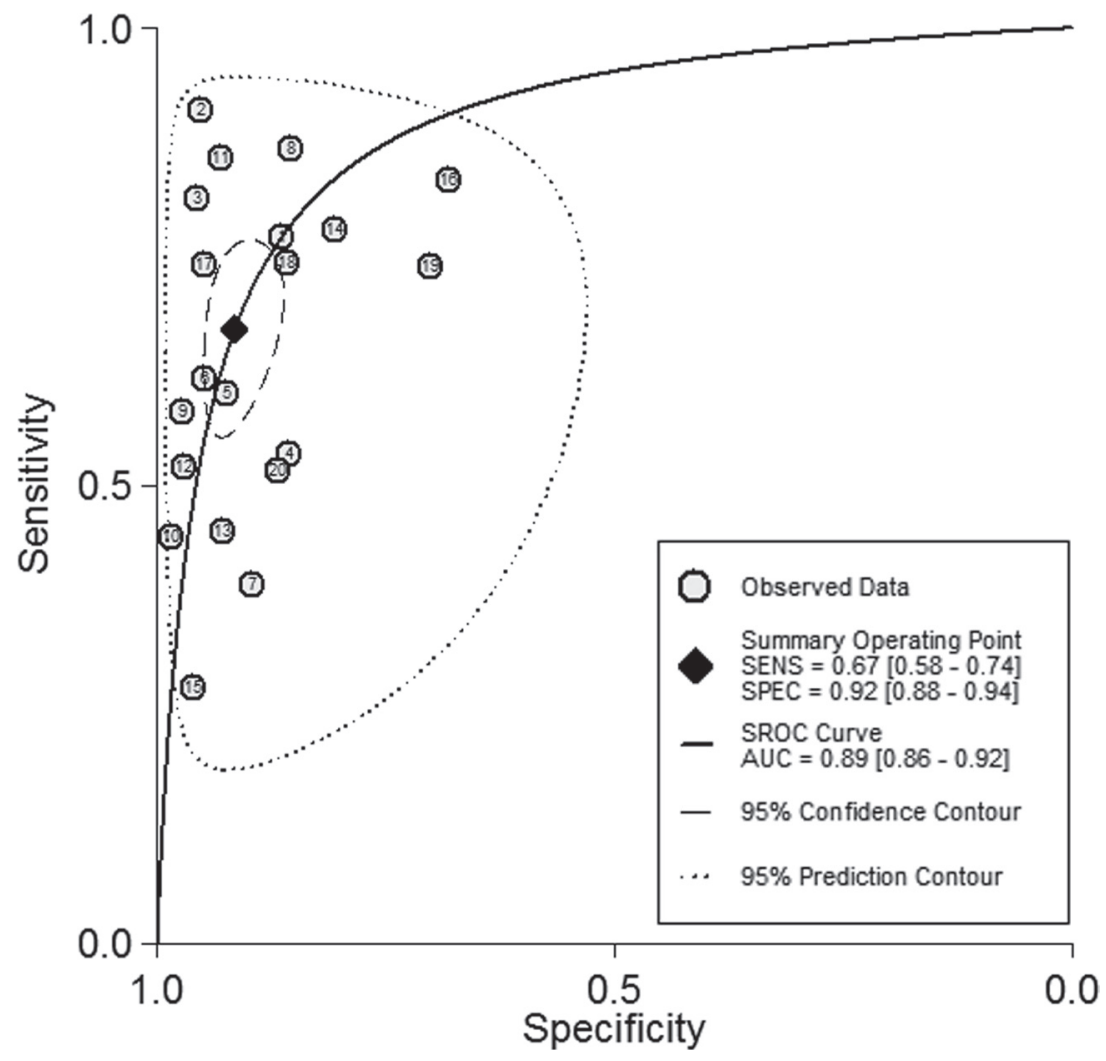

Figure 2. SROC curves from the bivariate model. The smaller region (confidence contour) contains likely combinations of the mean value of sensitivity and specificity. The wider region (prediction contour) demonstrates more uncertainty as to where the likely values of sensitivity and specificity might occur for individual studies. Note: SROC, summary receiver operating characteristic; SENS, sensitivity; SPEC, specificity.

the DCP performance by prospective design and 17 studies used the retrospective design. Diagnostic test accuracy may be overestimated in retrospective design, so these were regarded as not having a representative patient spectrum. Only 3 studies clearly stated that the DCP test results were interpreted blind to the results of the reference standard, 10 studies reported sufficient details of the index test and 5 studies clearly explained why patients withdraw from the study. The other items were reported well.

Data analysis. After analysis using the bivariate random effect model, the pooled sensitivity and specificity were $67 \%$ (95\%CI, 58\%-74\%) and 92\% (95\%CI, 88\%-94\%) respectively, the pooled PLR and NLR were $7.9(95 \% \mathrm{CI}, 5.6-11.2)$ and 0.36 (95\%CI, 0.29-0.46) respectively, and the pooled DOR was 22 (95\%CI, 14-34).

Figure 2 showed the bivariate sROC curve for the diagnostic accuracy of DCP, the area under the curve (AUC) was 0.89 (95\%CI, 0.85-0.92). Figure 2 also showed the summary point estimate of sensitivity and specificity. The smaller region $(95 \%$ confidence contour) contains likely combinations of the mean value of sensitivity and specificity. The wider region (95\% prediction contour) demonstrates more uncertainty as to where the likely values of sensitivity and specificity might occur for individual studies.
The Spearman correlation coefficient was $0.353, \mathrm{P}=0.126$, thus there was no effect of cut-off value. By means of the Cochran $\mathrm{Q}$ method and the test of $\mathrm{I}^{2}$, Cochran-Q=282.91, $\mathrm{P}=0.000 ; \mathrm{I}^{2}=99 \%$ (95\%CI, 99\%-100\%), which suggested significantly heterogeneity induced by factors other than cut-off effect.

With the bivariate random effect model, effects of covariates on sensitivity and specificity can be modelled separately. According to the meta-regression analysis, it was found that the covariates which had an effect on neither sensitivity nor specificity were: etiology (sensitivity $\mathrm{P}=0.18$; specificity $\mathrm{P}=0.57)$, gender $(\mathrm{P}=0.64$ for sensitivity and $\mathrm{P}=0.07$ for specificity) and small HCC ( $\mathrm{P}=0.08$ for sensitivity and $\mathrm{P}=0.26$ for specificity). The effects of ethnicity were significant on both sensitivity $(\mathrm{P}=0.02)$ and specificity $(\mathrm{P}=0.03)$. The effect of control was significant for specificity $(\mathrm{P}=0.01)$, but not for sensitivity $(\mathrm{P}=0.53)$. Therefore, subgroup analysis of ethnicity and control was made.

Table 2 showed the results of the subgroup analysis. Based on ethnicity, sensitivities calculated separately by studies of Asian and Caucasian were 63\% (95\%CI, 53\%-72\%) and 76\% (95\%CI, 61\%-87\%), specificities were 93\% (95\%CI, 89\%-96\%) and $88 \%$ (95\%CI, 80\%-93\%). Based on control, 9 studies used patients with chronic hepatitis and cirrhosis as control, pooled 
Table 2 Results of the subgroup analysis

\begin{tabular}{|c|c|c|c|c|c|c|c|}
\hline covariate & & Number of studies & Sens $(95 \%)$ & Spec(95\%) & DOR(95\%) & PLR(95\%) & $\operatorname{NLR}(95 \%)$ \\
\hline \multirow{2}{*}{ Ethnicity } & Asian & 14 & $\begin{array}{c}0.63 \\
(0.53-0.72)\end{array}$ & $\begin{array}{c}0.93 \\
(0.89-0.96)\end{array}$ & $\begin{array}{c}22.78 \\
(14.76-35.16)\end{array}$ & $\begin{array}{c}9.05 \\
(6.08-13.49)\end{array}$ & $\begin{array}{c}0.40 \\
(0.31-0.50)\end{array}$ \\
\hline & Caucasian & 6 & $\begin{array}{c}0.76 \\
(0.61-0.87)\end{array}$ & $\begin{array}{c}0.88 \\
(0.80-0.93)\end{array}$ & $\begin{array}{c}22.70 \\
(8.07-63.85)\end{array}$ & $\begin{array}{c}6.16 \\
(3.41-11.12)\end{array}$ & $\begin{array}{c}0.27 \\
(0.16-0.47)\end{array}$ \\
\hline \multirow{2}{*}{ Control } & $\mathrm{CH}$ and Cirrhosis & 9 & $\begin{array}{c}0.70 \\
(0.59-0.81)\end{array}$ & $\begin{array}{c}0.94 \\
(0.91-0.96)\end{array}$ & $\begin{array}{c}39.34 \\
(23.65-65.43)\end{array}$ & $\begin{array}{c}12.21 \\
(8.29-17.97)\end{array}$ & $\begin{array}{c}0.31 \\
(0.21-0.45)\end{array}$ \\
\hline & Cirrhosis & 11 & $\begin{array}{c}0.63 \\
(0.52-0.74)\end{array}$ & $\begin{array}{c}0.88 \\
(0.82-0.93)\end{array}$ & $\begin{array}{c}13.15 \\
(8.00-21.63) \\
\end{array}$ & $\begin{array}{c}5.43 \\
(3.64-8.10)\end{array}$ & $\begin{array}{c}0.41 \\
(0.31-0.55)\end{array}$ \\
\hline
\end{tabular}

Note: Sens, sensitivity; Spec, specificity; DOR, diagnostic odds ratio; PLR, positive likelihood ratio; NLR, negative likelihood ratio.
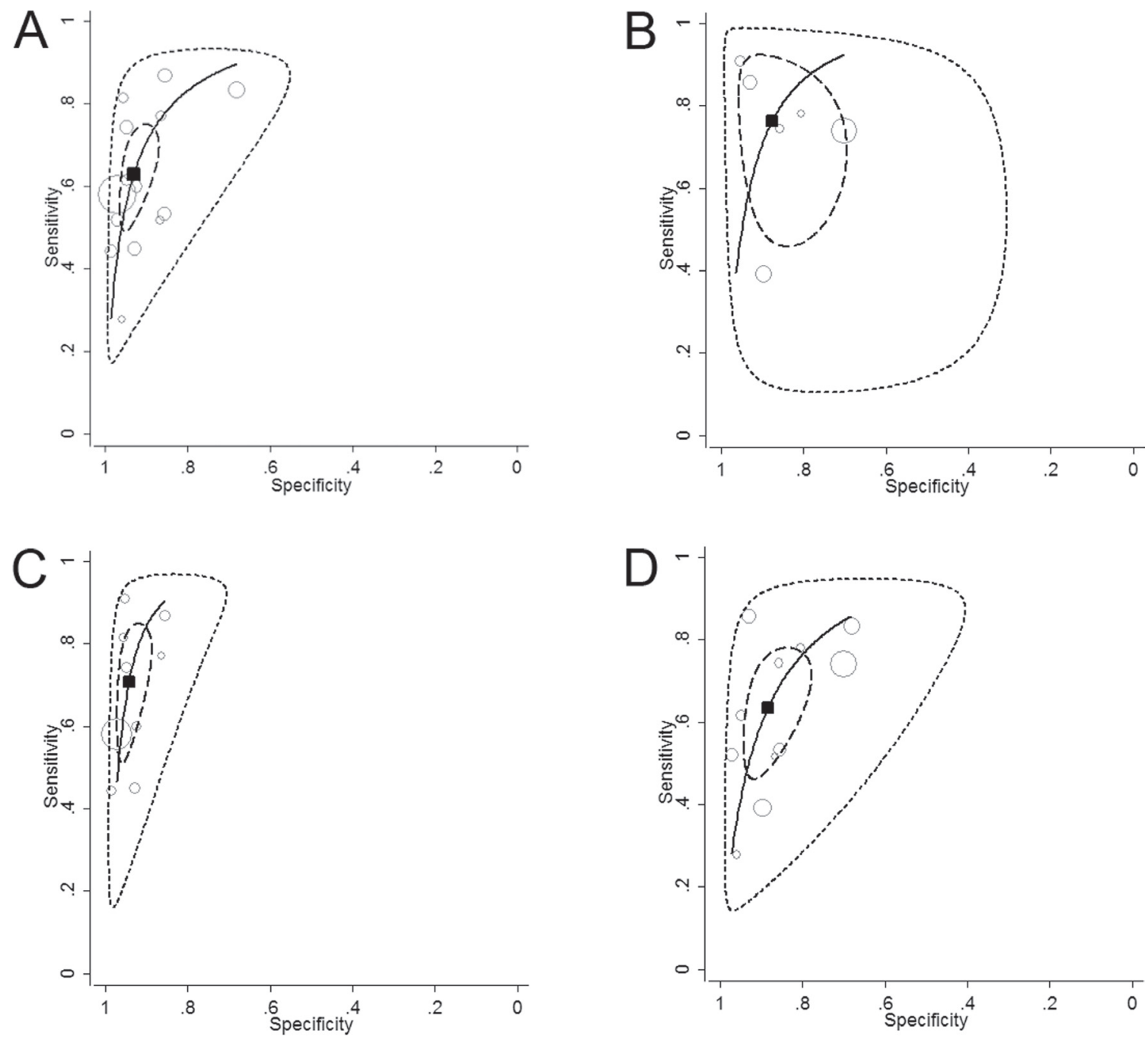

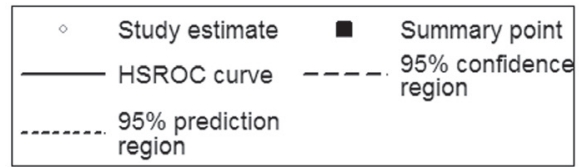

Figure 3. HSROC curve of the subgroup analysis. (A) HSROC curve of the subgroup of Asian. (B) HSROC curve of the subgroup of Caucasian. (C) HSROC curve of the subgroup in which patients with chronic hepatitis and cirrhosis were served as control. (D) HSROC curve of the subgroup in which patients with cirrhosis were served as control. Note: HSROC, hierarchical summary receiver operating characteristic. 


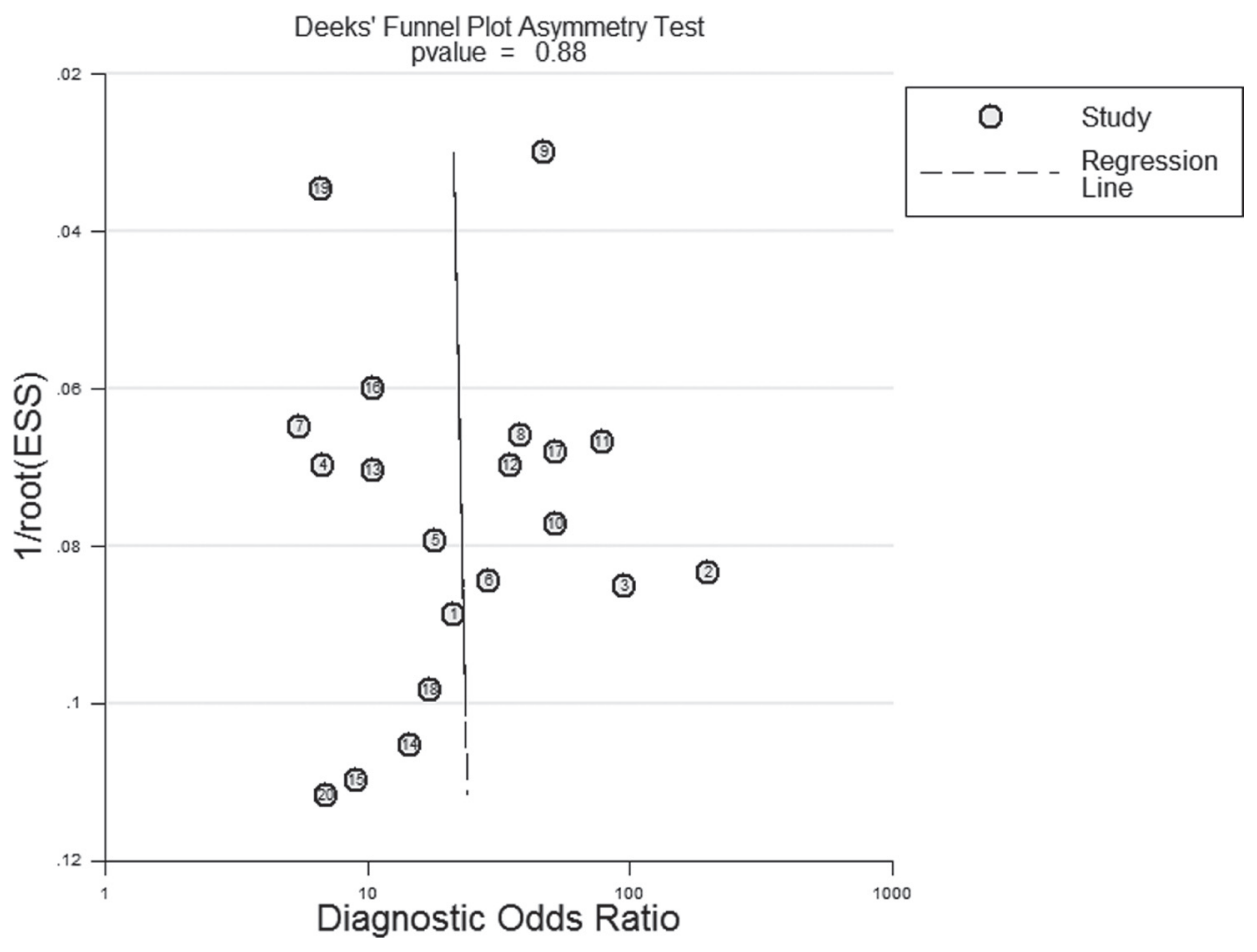

Figure 4. Deeks's funnel plot based on the data of the 20 studies. Note: ESS, effective sample size.

sensitivity and specificity calculated by these studies were $70 \%$ (95\%CI, 59\%-81\%) and 94\% (95\%CI, 91\%-96\%) respectively; 11 studies used patients with cirrhosis as control, pooled sensitivity and specificity were 63\% (95\%CI, 52\%-74\%) and $88 \%$ (95\%CI, 82\%-93\%) respectively. HSROC curves were also plotted to present the subgroup results (Figure 3).

The funnel plot of Deeks seemed symmetrical with a $\mathrm{P}=0.88$, which suggested a low risk of publication bias (Figure 4).

Clinical Utility of the Index test. Figure $5 \mathrm{~A}$ was the Probability Modifying Plot. Because HCC ultimately arises in $10-25 \%$ of patients with cirrhosis [43], $15 \%$ was selected as the pre-test probability. When a vertical line was drawn from 0.15 , it was found that the probability of HCC was approximately 0.6 if results were positive and the probability of HCC was 0.05 if negative. Fagan's nomograms demonstrated the same result (Figure 5B).

The likelihood ratio scattergram (Figure 6) showed that DCP is not useful for confirmation of HCC (when positive) and not for its exclusion (when negative) according to the summary point of likelihood ratios in the Right Lower Quadrant.

\section{Discussion}

As the number of HCC markers is growing rapidly, many clinicians, patients, researchers, and policy makers are confused as to the optimal measure. Serum DCP has attracted more attention because of its high specificity and lack of correlation with serum AFP levels. In this systematic review, the diagnostic accuracy of DCP for HCC was summarized. After rigorous screening, 20 studies (19 in English and 1 in Chinese) including a total of 5911 patients were eligible for inclusion. The pooled sensitivity and specificity were $67 \%$ (95\%CI, 58\%-74\%) and 92\% (95\%CI, 88\%-94\%) respectively, the pooled PLR and NLR were 7.9 (95\%CI, 5.6-11.2) and 0.36 (95\%CI, 0.29-0.46) respectively, the pooled DOR was 22 (95\%CI, 14-34), AUC was 0.89 (95\%CI, 0.85-0.92). The results of this meta-analysis suggested that the accuracy of DCP is perhaps less than initially described. In Marrero and colleagues' original study [31], the sensitivity and specificity were $89 \%$ and $95 \%$ respectively, AUC was 0.92 , all of the data were higher than those in our analysis. Because these studies were point estimates, we calculated summary sensitivities and specificities.

The clinical usefulness of a diagnostic test is largely determined by the accuracy with which it identifies its target disorder, and the accuracy measure relies on the likelihood ratios. Likelihood ratios of $>10$ or $<0.1$ generate large and often conclusive shifts from pre-test to post-test probability (indicating high accuracy); 5 to 10 or 0.1 to 0.2 generate moderate shifts in pre-test to post-test probability; 2 to 5 or 0.2 to 0.5 generate small changes in probability [44]. A PLR value of 7.9 suggests that the patients with HCC have an approximately 8 -fold higher chance of positive DCP assay compared with patients without HCC. High specificity is considered useful for confirmation of target disease, specificity in our review 

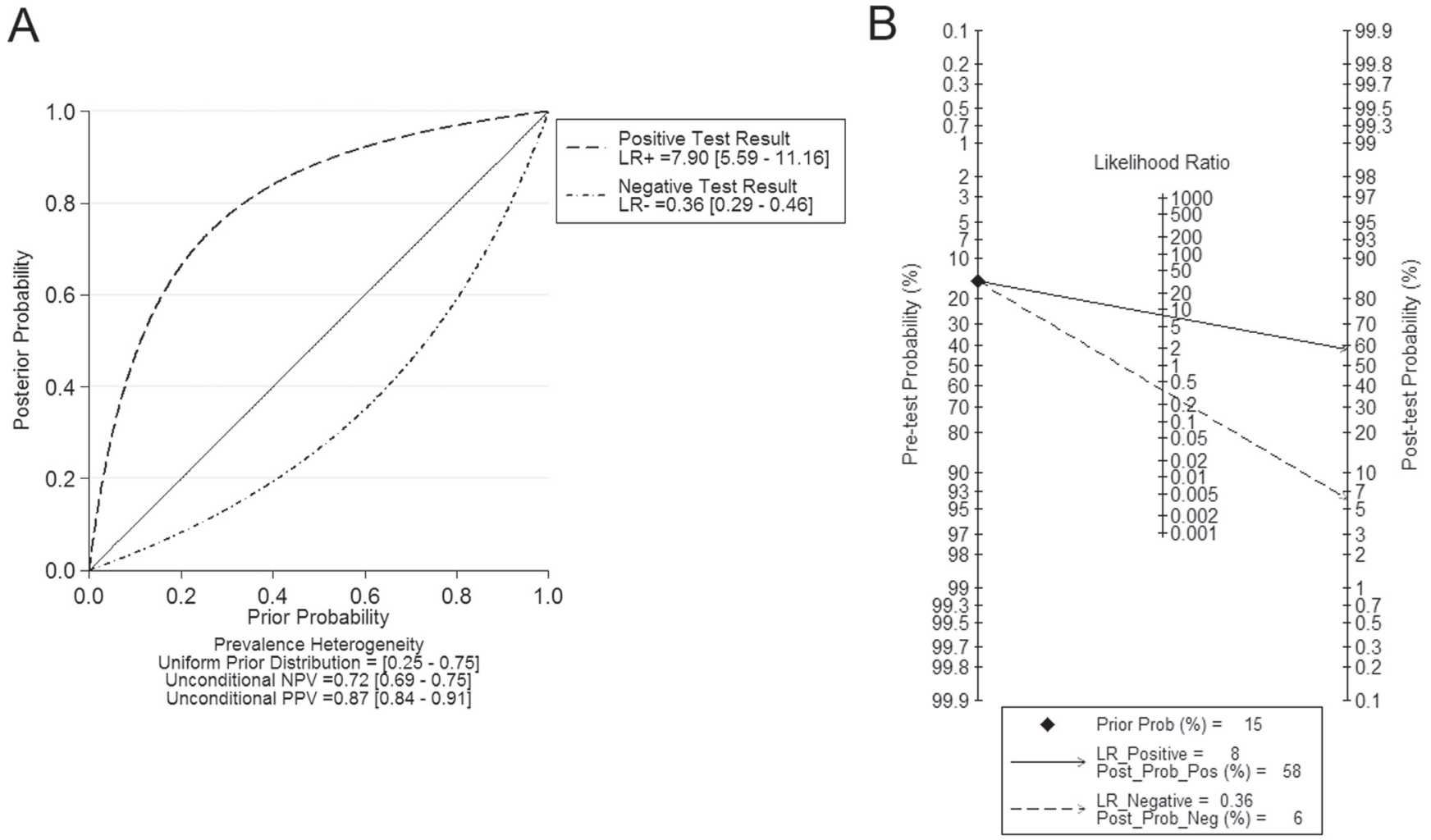

Figure 5. Post-test probabilities (PTPs) calculation. (A) Probability Modifying Plot for calculating PTPs. A vertical line was drawn from the selected pre-test probability to the appropriate likelihood ratio line and then reads the post-test probability off the vertical scale. (B) Fagan's nomogram for calculating post-test probabilities (PTPs). A straight edge was used to link the pretest probability of Hepatocellular carcinoma (HCC) with the PTP, by crossing the likelihood ratio line at a point that describes the results obtained.

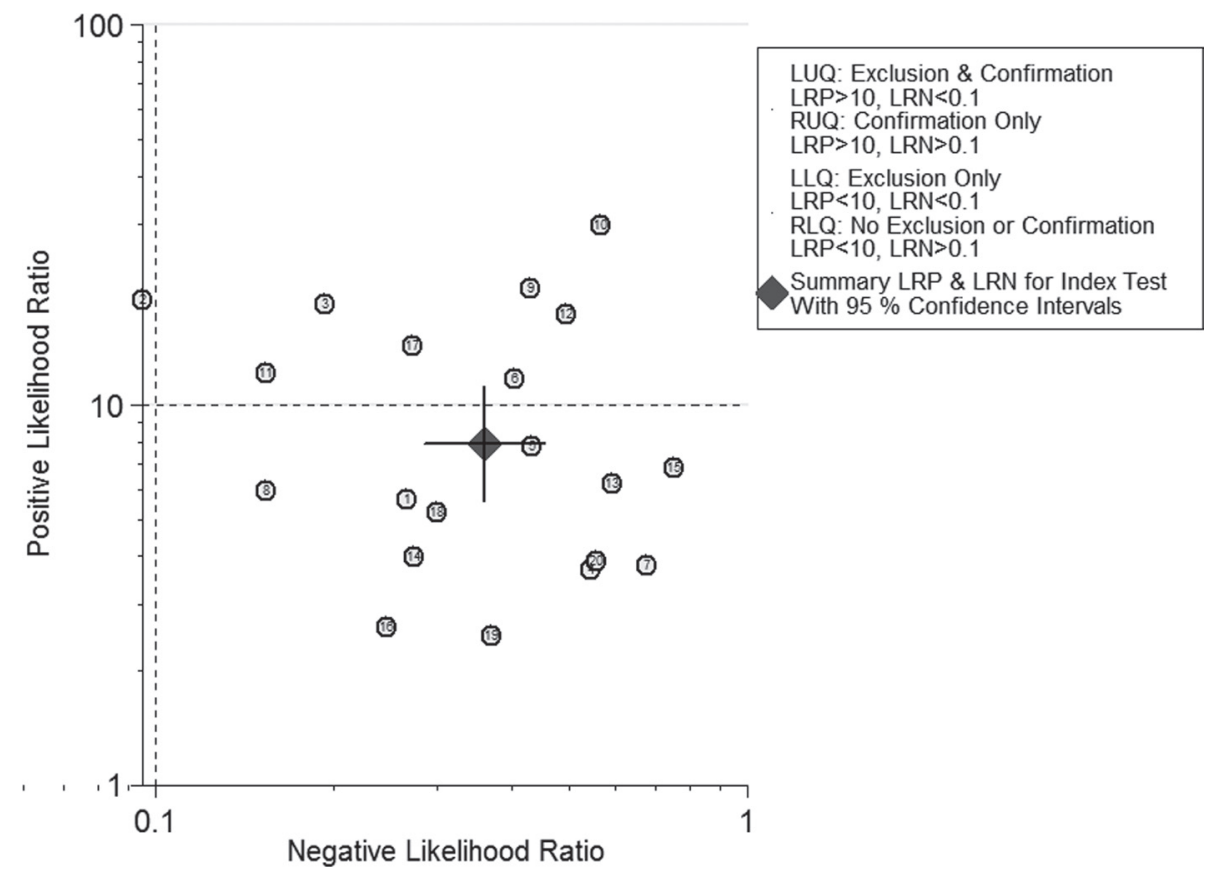

Figure 6. Likelihood ratio scatter gram. 
was $92 \%$, however due to its low sensitivity (sensitivity=67\%), the PLR did not reach 10, therefore the DCP test had modest confirmation of HCC. On the other hand, NLR was found to be 0.36 in the present meta-analysis. It is suggested that if the DCP assay result was negative, the probability that this patient suffers from HCC is approximately $36 \%$, which is not low enough to rule out HCC.

Heterogeneity is a potential problem when interpreting the results of all meta-analysis. It is one of the most important goals to explore the sources of heterogeneity in the meta-analysis. The heterogeneity may come from clinical characteristics such as ethnicity, etiology, tumor diameter, et al and methodological heterogeneity such as study design, blind, et al in the meta-analysis. As a result, the effects of ethnicity were significant on both sensitivity and specificity. The effect of control was significant for specificity, but not significant for sensitivity. In the subgroup analysis by ethnicity, sensitivity of Asian was lower than that of Caucasian, however the specificity was the reverse. This may be related to higher DCP values among Caucasian subjects without liver disease [31]. In the subgroup analysis by control, sensitivity and specificity of studies used patients with chronic hepatitis and cirrhosis as control were 70\% (95\%CI, 59\%-81\%) and 94\% (95\%CI, 91\%-96\%), which were both higher than the overall sensitivity and specificity. In this subgroup, the PLR reached 12.21, which generated large and often conclusive shifts from pre-test to post-test probability, suggesting that the DCP analysis was more useful in this subgroup.

To our knowledge, this meta-analysis was the first report that assessed the diagnostic ability of serum markers used for diagnosing HCC. Before this, only one article [45] attempted to assess the accuracy of AFP, but due to the widely variation, no summary estimates of sensitivity and specificity were obtainable. Also in this article, the accuracy of ultrasound scan (US), spiral computed (CT) and magnetic resonance imaging (MRI) had been systematically assessed. With respect to US, the sensitivity, specificity, PLR and NLR were 60\%, 97\%, 18 and 0.5 respectively. With respect to CT, the sensitivity, specificity, PLR and NLR were $68 \%, 93 \%, 6$ and 0.4 respectively. With respect to MRI, the sensitivity, specificity, PLR and NLR were $81 \%, 85 \%, 3.9$ and 0.3 respectively. Based on these results, DCP shows less diagnostic accuracy than US, but shows similar accuracy with CT, higher than MRI. Although DCP does not show excellent diagnostic value than other imaging technologies, DCP is still an attractive estimate of HCC. Besides, other serum markers should be assessed.

The strengths of this systematic review were its well defined search strategy, rigorous selection of study literature according to the inclusion criteria and more valid statistical model for diagnostic meta-analysis in the presence of heterogeneity. Of course, our review inevitably had a number of limitations. Firstly, in the 20 studies, 17 studies were retrospective design, only 3 were prospective design. Case-control study tends to overestimate or underestimate the diagnostic yield of a test, producing spectrum bias. Although it was not a covariate (sensitivity, $\mathrm{P}=0.17$; specificity, $\mathrm{P}=0.07$ ) in our meta-analysis, more prospective studies are needed in future. Secondly, HCC patients were few in some studies, this will lead to broad variance about sensitivity. Finally, although subgroup analysis and sensitivity analysis were performed by covariates, the heterogeneity was not wholly eliminated. If heterogeneity analysis was performed in the subgroup, potential bias might occur due to few studies were included.

In summary, our systematic review suggests that DCP has moderate diagnostic utility for the diagnosis of HCC. Its major role appears to be the moderate confirmation of HCC. More prospective studies of DCP are needed in future. Then meta-analysis should perform more accurately. Besides, novel HCC biomarker with improved accuracy should be applied in future.

Acknowledgments: The article was supported by National Natural Science Foundation of China (No. 30972516) and Natural Science Foundation of Hebei Province, China (No. C2010000481). Ping Gao conceived and designed the research; Ping Gao and Man Li performed the experiments and analyzed the data; Ping Gao and Dian-Wu Liu wrote the paper.

\section{References}

[1] BOSCH FX, RIBES J, DIAZ M, CLERIES R. Primary liver cancer: worldwide incidence and trends. Gastroenterology 2004; 127: S5-S16. http://dx.doi.org/10.1053/j.gastro.2004.09.011

[2] PARKIN DM, BRAY F, FERLAY J, PISANI P. Estimating the world cancer burden: Globocan 2000. Int J Cancer 2001; 94: 153-156. http://dx.doi.org/10.1002/ijc.1440

[3] FARMER DG, ROSOVE MH, SHAKED A, BUSUTTIL RW. Current treatment modalities for hepatocellular carcinoma. Ann Surg 1994; 219: 236-247.

[4] BRUIX J, SHERMAN M. Management of hepatocellular carcinoma. Hepatology 2005; 42: 1208-1236. http://dx.doi. org/10.1002/hep.20933

[5] LLOVET JM, SCHWARTZ M, MAZZAFERRO V. Resection and liver transplantation for hepatocellular carcinoma. Semin Liver Dis 2005; 25: 181-200.

[6] LIAW YF, TAI DI, CHU CM, LIN DY, SHEEN IS et al. Early detection of hepatocellular carcinoma in patients with chronic type B hepatitis. A prospective study. Gastroenterology 1986; 90: 263-267.

[7] ZHANG BH, YANG BH, TANG ZY. Randomized controlled trial of screening for hepatocellular carcinoma. J Cancer Res Clin Oncol 2004; 130: 417-422.

[8] FRANCA AV, ELIAS JUNIOR J, LIMA BL, MARTINELLI AL, CARRILHO FJ. Diagnosis, staging and treatment of hepatocellular carcinoma. Braz J Med Biol Res 2004; 37: 1689-1705.

[9] TONG MJ, BLATT LM, KAO VW. Surveillance for hepatocellular carcinoma in patients with chronic viral hepatitis in the United States of America. J Gastroenterol Hepatol 2001; 16: 553-559. http://dx.doi.org/10.1046/j.1440-1746.2001.02470.x

[10] CHEN DS, SUNG JL, SHEU JC, LAI MY, HOW SW et al. Serum alpha-fetoprotein in the early stage of human hepatocellular carcinoma. Gastroenterology 1984; 86: 1404-1409. 
[11] DI BISCEGLIE AM, HOOFNAGLE JH. Elevations in serum alpha-fetoprotein levels in patients with chronic hepatitis B. Cancer 1989; 64: 2117-2120. http://dx.doi.org/10.1002/1097-014 2(19891115)64:10<2117::AID-CNCR2820641024>3.0.CO;2-7

[12] LIEBMAN HA, FURIE BC, TONG MJ, BLANCHARD RA, LO KJ et al. Des-gamma-carboxy (abnormal) prothrombin as a serum marker of primary hepatocellular carcinoma. $\mathrm{N}$ Engl J Med 1984; 310: 1427-1431. http://dx.doi.org/10.1056/ NEJM198405313102204

[13] BRUIX J, SHERMAN M, LLOVET JM, BEAUGRAND M, LENCIONI R et al. Clinical management of hepatocellular carcinoma. Conclusions of the Barcelona-2000 EASL conference. European Association for the Study of the Liver. J Hepatol 2001; 35: 421-430.

[14] WHITING P, RUTJES AW, REITSMA JB, BOSSUYT PM, KLEIJNEN J. The development of QUADAS: a tool for the quality assessment of studies of diagnostic accuracy included in systematic reviews. BMC Med Res Methodol 2003; 3: 25. http://dx.doi.org/10.1186/1471-2288-3-25

[15] WHITING P, HARBORD R, KLEIJNEN J. No role for quality scores in systematic reviews of diagnostic accuracy studies. BMC Med Res Methodol 2005; 5: 19. http://dx.doi. org/10.1186/1471-2288-5-19

[16] REITSMA JB, GLAS AS, RUTJES AW, SCHOLTEN RJ, BOSSUYT PM et al. Bivariate analysis of sensitivity and specificity produces informative summary measures in diagnostic reviews. J Clin Epidemiol 2005; 58: 982-990. http://dx.doi. org/10.1016/j.jclinepi.2005.02.022

[17] HIGGINS JP, THOMPSON SG. Quantifying heterogeneity in a meta-analysis. Stat Med 2002; 21: 1539-1558. http://dx.doi. org/10.1002/sim.1186

[18] HARBORD RM, WHITING P, STERNE JA, EGGER M, DEEKS JJ et al. An empirical comparison of methods for meta-analysis of diagnostic accuracy showed hierarchical models are necessary. J Clin Epidemiol 2008; 61: 1095-1103. http://dx.doi.org/10.1016/j.jclinepi.2007.09.013

[19] DEEKS JJ, MACASKILL P, IRWIG L. The performance of tests of publication bias and other sample size effects in systematic reviews of diagnostic test accuracy was assessed. J Clin Epidemiol 2005; 58: 882-893. http://dx.doi.org/10.1016/ j.jclinepi.2005.01.016

[20] SEVERENS JL, SONKE G, LAHEIJ RJ, VERBEEK AL, DE VRIES ROBBE PF. Efficient diagnostic test sequence: applications of the probability-modifying plot. J Clin Epidemiol 2001; 54: 1228-1237. http://dx.doi.org/10.1016/ S0895-4356(01)00391-2

[21] FAGAN TJ. LETTER: Nomogram for Bayes theorem. N Engl J Med 1975; 293: 257. http://dx.doi.org/10.1056/ NEJM197507312930513

[22] STENGEL D, BAUWENS K, SEHOULI J, EKKERNKAMP A, PORZSOLT F. A likelihood ratio approach to meta-analysis of diagnostic studies. J Med Screen 2003; 10: 47-51. http://dx.doi. org/10.1258/096914103321610806

[23] BACHTIAR I, KHENG V, WIBOWO GA, GANI RA, HASAN I et al. Alpha-1-acid glycoprotein as potential biomarker for alpha-fetoprotein-low hepatocellular carcinoma. BMC Res Notes 2010; 3: 319.
[24] BAEK YH, LEE JH, JANG JS, LEE SW, HAN JY et al. Diagnostic role and correlation with staging systems of PIVKA-II compared with AFP. Hepatogastroenterology 2009; 56: 763 767.

[25] BEALE G, CHATTOPADHYAY D, GRAY J, STEWART S, HUDSON M et al. AFP, PIVKAII, GP3, SCCA-1 and follisatin as surveillance biomarkers for hepatocellular cancer in nonalcoholic and alcoholic fatty liver disease. BMC Cancer 2008; 8: 200. http://dx.doi.org/10.1186/1471-2407-8-200

[26] CUI R, HE J, ZHANG F, WANG B, DING H et al. Diagnostic value of protein induced by vitamin $\mathrm{K}$ absence (PIVKAII) and hepatoma-specific band of serum gamma-glutamyl transferase (GGTII) as hepatocellular carcinoma markers complementary to alpha-fetoprotein. Br J Cancer 2003; 88: 1878-1882. http://dx.doi.org/10.1038/sj.bjc.6601018

[27] DURAZO FA, BLATT LM, COREY WG, LIN JH, HAN S et al. Des-gamma-carboxyprothrombin, alpha-fetoprotein and AFP-L3 in patients with chronic hepatitis, cirrhosis and hepatocellular carcinoma. J Gastroenterol Hepatol 2008; 23: 1541-1548. http://dx.doi.org/10.1111/j.1440-1746.2008.05395.x

[28] KUROMATSU R, TANAKA M, SHIMAUCHI Y, SHIMADA M, TANIKAWA K et al. Usefulness of ED036 kit for measuring serum PIVKA-II levels in small hepatocellular carcinoma. J Gastroenterol 1997; 32: 507-512. http://dx.doi.org/10.1007/ $\underline{B F 02934091}$

[29] LOK AS, STERLING RK, EVERHART JE, WRIGHT EC, HOEFS JC et al. Des-gamma-carboxy prothrombin and alpha-fetoprotein as biomarkers for the early detection of hepatocellular carcinoma. Gastroenterology 2010; 138: 493502. http://dx.doi.org/10.1053/j.gastro.2009.10.031

[30] MARRERO JA, FENG Z, WANG Y, NGUYEN MH, BEFELER AS et al. Alpha-fetoprotein, des-gamma carboxyprothrombin, and lectin-bound alpha-fetoprotein in early hepatocellular carcinoma. Gastroenterology 2009; 137: 110-118.

[31] MARRERO JA, SU GL, WEI W, EMICK D, CONJEEVARAM HS et al. Des-gamma carboxyprothrombin can differentiate hepatocellular carcinoma from nonmalignant chronic liver disease in american patients. Hepatology 2003; 37: 1114-1121. http://dx.doi.org/10.1053/ihep.2003.50195

[32] MITA Y, AOYAGI Y, YANAGI M, SUDA T, SUZUKI Y et al. The usefulness of determining des-gamma-carboxy prothrombin by sensitive enzyme immunoassay in the early diagnosis of patients with hepatocellular carcinoma. Cancer 1998; 82: 1643-1648. http://dx.doi.org/10.1002/(SICI)10970142(19980501)82:9<1643::AID-CNCR8>3.0.CO;2-B

[33] NAKAMURA S, NOUSO K, SAKAGUCHI K, ITO YM, OHASHI Y et al. Sensitivity and specificity of des-gamma-carboxy prothrombin for diagnosis of patients with hepatocellular carcinomas varies according to tumor size. Am J Gastroenterol 2006; 101: 2038-2043. http://dx.doi. org/10.1111/j.1572-0241.2006.00681.x

[34] NOMURA F, ISHIJIMA M, KUWA K, TANAKA N, NAKAI $\mathrm{T}$ et al. Serum des-gamma-carboxy prothrombin levels determined by a new generation of sensitive immunoassays in patients with small-sized hepatocellular carcinoma. Am J Gastroenterol 1999; 94: 650-654. http://dx.doi.org/10.1111/ j.1572-0241.1999.00930.x 
[35] OKUDA H, NAKANISHI T, TAKATSU K, SAITO A, HAYASHI $\mathrm{N}$ et al. Measurement of serum levels of desgamma-carboxy prothrombin in patients with hepatocellular carcinoma by a revised enzyme immunoassay kit with increased sensitivity. Cancer 1999; 85: 812-818. http://dx.doi. org/10.1002/(SICI)1097-0142(19990215)85:4<812::AIDCNCR8 $>3.0$. CO;2-O

[36] SASSA T, KUMADA T, NAKANO S, UEMATSU T. Clinical utility of simultaneous measurement of serum high-sensitivity des-gamma-carboxy prothrombin and Lens culinaris agglutinin A-reactive alpha-fetoprotein in patients with small hepatocellular carcinoma. Eur J Gastroenterol Hepatol 1999; 11: 1387-1392. http://dx.doi.org/10.1097/00042737-199912000-00008

[37] SHARMA B, SRINIVASAN R, CHAWLA YK, KAPIL S, SAINI N et al. Clinical utility of prothrombin induced by vitamin $\mathrm{K}$ absence in the detection of hepatocellular carcinoma in Indian population. Hepatol Int 2010; 4: 569-576. http://dx.doi. org/10.1007/s12072-010-9186-2

[38] STERLING RK, JEFFERS L, GORDON F, VENOOK AP, REDDY KR et al. Utility of Lens culinaris agglutinin-reactive fraction of alpha-fetoprotein and des-gamma-carboxy prothrombin, alone or in combination, as biomarkers for hepatocellular carcinoma. Clin Gastroenterol Hepatol 2009; 7: 104-113. http://dx.doi.org/10.1016/j.cgh.2008.08.041

[39] VOLK ML, HERNANDEZ JC, SU GL, LOK AS, MARRERO JA. Risk factors for hepatocellular carcinoma may impair the performance of biomarkers: a comparison of AFP, DCP, and AFP-L3. Cancer Biomark 2007; 3: 79-87.
[40] WANG CS, LIN CL, LEE HC, CHEN KY, CHIANG MF et al. Usefulness of serum des-gamma-carboxy prothrombin in detection of hepatocellular carcinoma. World J Gastroenterol 2005; 11: 6115-6119.

[41] YOON YJ, HAN KH, KIM DO Y. Role of serum prothrombin induced by vitamin $\mathrm{K}$ absence or antagonist-II in the early detection of hepatocellular carcinoma in patients with chronic hepatitis B virus infection. Scand J Gastroenterol 2009; 44: 861-866. http://dx.doi.org/10.1080/00365520902903034

[42] XH C, RT C, BE W, JD J, FK Z et al. The Diagnostic Value of the Des-gamma-Carboxy Prothrombic Caused by the Vitamin $\mathrm{K}$ Absence in the Hepatic Carcinoma. Chinese Journal of Clinical Gastroenterology 2002: 156-159.

[43] SCHUPPAN D, AFDHAL NH. Liver cirrhosis. Lancet 2008; 371: 838-851. http://dx.doi.org/10.1016/S0140-6736(08)60383$\underline{9}$

[44] JAESCHKE R, GUYATT GH, SACKETT DL. Users' guides to the medical literature. III. How to use an article about a diagnostic test. B. What are the results and will they help me in caring for my patients? The Evidence-Based Medicine Working Group. JAMA 1994; 271: 703-707. http://dx.doi. org/10.1001/jama.271.9.703

[45] COLLI A, FRAQUELLI M, CASAZZA G, MASSIRONI S, COLUCCI A et al. Accuracy of ultrasonography, spiral $\mathrm{CT}$, magnetic resonance, and alpha-fetoprotein in diagnosing hepatocellular carcinoma: a systematic review. Am J Gastroenterol 2006; 101: 513-523. http://dx.doi.org/10.1111/ j.1572-0241.2006.00467.x 